\title{
Infrastructure and Convergence in the EU: Introduction
}

\author{
Massimo Florio
}

Published online: 20 June 2010

(C) Springer-Verlag 2010

This Special Issue of Transition Studies Review on "Infrastructure, convergence and investment decisions in the EU", is a collection of selected papers presented at the VIII Milan European Economy Workshop (11 and 12 June 2009) in the context of the EIBURS project on "Public investment under budgetary constraints in new member states", funded by the European Investment Bank. The Department of Economics, Business and Statistics, DEAS (Università degli Studi, di Milano, Italy), in partnership with CERGE-EI (Charles University, Prague), with a network of international experts in the EU Member States, has addressed issues related to public investment in infrastructure by a combination of theoretical and empirical analysis, with a particular attention given to offering recommendations to bodies in charge of budgetary and investment decisions.

The research papers included in this Special Issue aim at analyzing public investment in the European Union, with an explicit focus on the New Member States in the presence of financial constraints (for the related papers see Florio 2011). The contributions address important issues related to infrastructure public investment by adopting different perspectives and techniques. The main conclusions relate to the choice of methods of funding and to the evaluation of different projects and schemes in the presence of fiscal constraints, an issue of paramount importance for the EU New Member States and offer a novel perspective on the growth potential of public investment in regional and national European economies.

Below I briefly summarise the papers and then conclude by providing some personal remarks.

The findings, views and policy implications expressed in these papers are entirely those of the authors, and do not necessarily represent the views of the European Investment Bank.

M. Florio $(\bowtie)$

Department of Economics, Business and Statistics, Università degli Studi di Milano, Milan, Italy

e-mail: massimo.florio@unimi.it 
Economic growth implications of infrastructure investment at the regional and national level are analyzed in the contribution by Del Bo, Florio and Manzi ("Regional infrastructure and convergence: growth implications in a spatial framework").

The paper contributes to the debate on convergence, by presenting an overview of the catch up process of the EU regions between 1995 and 2006, focusing on both absolute and conditional convergence.

The focus is on the role of infrastructure stock in shaping the growth and convergence process between EU regions and to what extent the spatial dimension of the data affects results. The paper also explicitly examines the link between infrastructure evolution and regional economic growth with a spatial panel data approach. The main results confirm an ongoing convergence process at the EU regional level, and assess the important role of transport and telecommunication infrastructure, with traditional and spatial estimation techniques. The authors also confirm, in a panel setting, the strong positive correlation between transport and TLC indicators and GDP growth at the regional level.

After this "macro" perspective, we turn to financing decisions.

The paper by Malcolm Sawyer ("Public private partnerships, the levels of public investment and the new member states") outlines some of the features of public private partnerships (PPPs). The arguments that PPPs provide additional investment are critically examined, and the way in which the accounting treatment may influence the use of PPPs are considered. The costs of PPPs are compared with 'conventional' public investment and it is argued that PPPs are a relatively expensive way of undertaking public investment. The idea that PPPs effectively transfer risk from government to private companies is assessed. Issues relating to the nature of contracts under PPPs, the transactions costs and the implementation of the contracts, are briefly considered. For the New Member States, it is suggested that national accounting rules and perceived constraints on budget deficits may encourage the use of PPPs, even if that use is not warranted in terms of costs of public investment.

The issue of PPP financing is also critically examined by Massimo Cingolani.

A model of the monetary circuit is applied to the costs and benefits of public or private financing of transport infrastructure with particular focus on roads ("PPP financing in the road sector: a disequilibrium analysis based on the monetary vircuit"). The author discusses public and private financing of infrastructure against the background of monetary equilibria. By analyzing "disequilibrium positions", where there is violation of some of the optimality conditions that define the neoclassical barter equilibrium, money is not neutral and financing has an impact on allocation through distribution. Evaluating welfare before and after the realization of a project implies a comparison between two suboptimal positions. Such a comparison reveals that there are not many arguments to prefer private financing to public financing of road infrastructure, particularly where local incomes are low. Post-Keynesian analysis in general and its monetary variant of the circuit, are useful tools for the analysis of public investment policies in such a disequilibrium context. In particular, some features of the monetary circuit approach are well suited to address the economic problems raised by the analysis of PPP, notably: (a) the 
integration of the banking sector and the recognition of its role in monetary creation by the private sector; (b) the monetary creation by the State within a macroeconomic framework fully integrating public finance; and (c) the necessary link between uncertainty and disequilibrium. Combined with a partial equilibrium analysis based on realistic microeconomic configurations of costs and transport demand parameters, the analysis of the circuit highlights that PPP in the road sector do not add anything to the level of effective demand, being in fact the other flip of the coin of restrictive budgetary policies. PPP play a role in mobilizing part of the accumulated savings that the State is forbidden to attract directly because of debt ceilings. They have a softening effect on the Government budgetary constraints similar to those that could be reached if the Government was allowed to accrue investment like the private sector, but are a less transparent solution, because the relevant debt is not necessarily recognized in the balance sheet that services it.

Investment decisions and cost-benefit analysis are considered by the two subsequent papers.

The contribution by de Rus and Socorro ("Infrastructure investment and incentives with supranational funding") is centred on the selection of public infrastructure projects co-funded by supranational organizations. The authors show that the type of institutional design regarding the financing mechanism affects the incentives of national governments to reduce costs and increase revenues, affecting project selection, the infrastructure capacity, the choice of technology, and the type of contract used for the construction and operation of projects. With a total cost-plus financing mechanism there is no incentive in being efficient and the price charged for the use of the new infrastructure is zero, the market quantity excessive, and the level of supranational financing disproportionate. In contrast, with a sunk cost-plus financing mechanism, social optimal pricing is always implemented, though there is no incentive in being efficient. Finally, with a fixed-price financing mechanism the maximal efficiency may be achieved, and the socially optimal pricing is always implemented.

The paper by Emile Quinet ("Issues of price definition in CBA: imperfect competition, budget constraints and relative prices divergences") assesses the consequences of ignoring the strategic interactions between operators involved in the new infrastructure and their consequences on the prices of transport services which should be endogenously determined by the market structure. The paper also shows how it is possible to optimize programs when, for one reason or another, the current discount rate does not allow implementing all profitable schemes, in other words when a budget constraint remains. Finally, it explores the consequences of changing relative prices in the case of environmental goods, and extending sufficiently the time horizon in order to take into account these relative changes may lead to conclusions very different from the usual results of current CBA practice, and for instance reconcile individual CBA results with the current macro economic debate on GHG effects.

Finally, the paper by Del Bo and Florio ("Cost-benefit analysis and the rates of return of infrastructure projects: evidence from international organizations") analyses data on the rates of return of a large number of investment projects sponsored by three international institutions: the European Union, the European 
Bank for Reconstruction and Development, the World Bank. The focus of the paper is on the variability of ex-ante economic rate of returns (ERR), of financial rates of return (FRR, available for EU and EBRD) and ex-post or re-estimated economic rates of return (RERR, available for WB only). The authors propose a framework of analysis of FRR and ERR variations across projects, sectors, financing institutions, of the wedge between ERR and FRR, and of the gap between ERR and RERR. In principle the same framework could be used for comparing rates of return variability of development projects across countries, time of approval or completion, or any other relevant sampling criterion.

I hope that, taken together, this set of papers will contribute to the debate on how to implement a sustainable long-term investment strategy in the New Member States of the EU.

First, they show that there is a serious case for using infrastructure investment plans as a necessary mechanism to achieve real convergence among European economies. This is a goal that the recent global crisis and the disruption of the public finance of Greece and other EU Members have just made more difficult, but also more compelling. Both theory, particularly in a post-Keynesian frame, and empirics, offer convincing arguments in favour of reviving major public investment plans in this context.

Second, not all implementation mechanisms are equally valuable. The case for public-private partnerships has been exaggerated, and bond government-backed finance of public infrastructure or securities by supra-national bodies seem today often more attractive than other alternatives. At the same time, governments should consider carefully the contractual arrangements in which they enter with private firms, even when they act through procurement contracts. Here incentive theory has something to say, as it shows that cost reimbursement is often an invitation to dissipate socially valuable public money.

Third, cost-benefit analysis is still an important tool for decision, but oversimplification and ad hoc procedures must be avoided. A systematic and transparent economic evaluation of projects by international and national bodies is the cornerstone of any public investment design for the future.

Acknowledgments Funding under the EIB-Universities Research Action from the European Investment Bank is gratefully acknowledged.

\section{Reference}

Florio M (ed) (2011) Public investment, growth and fiscal constraints: challenges for the EU new member states. Edward Elgar Publishing (forthcoming) 